\title{
COMBINATION ASSESSMENT MODEL STUDY OF THE WATER QUALITY OF THE YANGTZE RIVER
}

\author{
Peng Yongxing and Hu Lijun \\ Informatics College \& Business Administration College of Zhongnan University of Economics \& Law \\ 114 Wuluo Road, Wuhan, Hubei 430064, P.R.China \\ paley_pl@Yahoo.com / ljhu@public.wh.hb.cn
}

\begin{abstract}
Keywords: Water-quality, Fuzzy Assessment, Group AHP, Combination Evaluation
Summary: The water resource of China is not abundant. Yangtze River is the biggest river of China. With the prompt development of economies and the quick growth of population, water pollution is becoming worse and worse, these hasten the shortage of Water resource. Protecting the water resource of Yangtze River is significant to the realization of the continuous development strategy of the Society \& Economies of China. Aiming at the deficiency of present water-quality assessment method, this article adopts the combination evaluation method of Group AHP and Fuzzy Assessment; presents a new evaluating method which combines two or two more water-quality evaluating models into a type of new one; assesses and analyzes the water-quality of the main streams of the Yangtze River's middle reaches and makes the present water-quality assessment more scientific, rational and practical.
\end{abstract}

\section{Introduction}

China's water resource is of relative shortage. On average, the water resource for one person is less than $1 / 4$ below the world average. With the rapid development of economies and the quickly growing population, water pollution is being deteriorating. The shortage of water is getting dramatic. According to a primary statistics in 600 cities of China, running short of water are about half of the cities there, especially in the northern regions. And thus there is rather a severe shortage of water. The economic loss caused by the shortage is over RMB $¥ 1000$ billion (US\$ 120 billion).

Just as some economists pointed out that the bottle-neck factors which restrict the development of social economy in the 20th century are power-resource and traffic, while it will be the water-resource in the $21 \mathrm{st}$ century. And therefore, in order to solve the serious problems of water shortage in northern regions, China's government plans to invest large amount of funds on the planning and building of the project called 'transfer water from the south to the north'.

The biggest river in China is Yangtze River, which runs through 11 provinces, cities and autonomous regions. The drainage area is about $1 / 5$ of the total area of China; the population in this area is about $1 / 3$ of the national population; the gross industrial and agricultural output is about $40 \%$ of the GNP.

Yangtze River is the main traffic artery traveling from the West to the East. A prosperous economic belt has come into being along the river. The developing history in the reaches of the river is quite long. The human being's frequent activities did great damage to the ecology environment. Especially in recent decades, numerous industrial enterprises boomed along either of the riversides and population increased quickly. Serious water-erosion and water-pollution have done great harm to industrial and agricultural production and people's health. So working out the water-environment protecting program in Yangtze River, enhancing the water-quality monitor, studying the water-quality assessing methods have brooked no delay to realize the continuous development strategy of the national finance and the social progress. 
Scientific and reasonable water-quality evaluation benefits learning the situation of water-environment, exploiting and utilizing water resource reasonably; predicting the varying tendency of water-environment in the future. Applying mathematics models to do quantitative description on water-quality assessment is a commonly adopted method at home and abroad, but there is not such a single water-quality assessing model that is generally recognized. As in the process of water-quality evaluation, the pollution degree and the classification of water-quality grading and other factors are fuzzy to the extent. Since 1980s, China has started to apply fuzzy mathematic method to study the water-quality evaluation and has made great achievements. At present, among the usually adopted water-quality evaluating methods are Simply Index Method, Grades Scoring Method, Statistics Analysis Method, Fuzzy Mathematic Methods etc. These methods respectively have their strengths and weaknesses. Comparatively, fuzzy combination evaluating method pays full attention to the fuzziness of the bounds of water-quality grades, and it can reflect the real situation of water-quality, and has been put to wide use. To the great extent, the effectiveness of fuzzy combination evaluation relies on the definition of the weights of evaluating indices. Different evaluating models give rise to inconsistent evaluation results, and sometimes rather different, which usually makes people confused. By applying Group AHP method in this article, we attempt to put forward a new type of evaluating method to effectively define the index weights of water-quality; by setting up suitable models, we combine two or two more represented evaluating methods into a type of new model. It fully utilizes all kinds of useful assessing information to combine their mutual strengths to offset their own weaknesses and complements each others and makes the fuzziness of water-quality assessment more scientific and reliable.

\section{Principle of Water-Quality Fuzzy Assessment}

As in the water-quality assessment, pollution extent, water-quality variety, grading boundary and other factors objectively are vague to some extent, so that adopting fuzzy evaluation method to do the assessment is reasonable. According to the National Standards of water-quality evaluation, suppose totally $t$ stands for grades water-quality-standard and $n$ for items of evaluation-index. The standard-concentration-value of the No. $j$ index of the No. $k$ grade water-quality is $s_{k j}(\mathrm{mg} / 1)(k=1$, $2, \ldots, t ; \quad j=1,2, \ldots, n)$. So that the Standard-Concentration-Matrix of water-quality grading is:

$$
\boldsymbol{S}=\left(s_{k j}\right)_{t \times n}=\left[\begin{array}{cccc}
s_{11} & s_{12} & \cdots & s_{1 n} \\
s_{21} & s_{22} & \cdots & s_{2 n} \\
\vdots & \vdots & \vdots & \vdots \\
s_{t 1} & s_{t 2} & \cdots & s_{t n}
\end{array}\right]
$$

Now there are $m$ polluted water samples, each sample has $\mathrm{n}$ types of evaluation index, the actual testing-value of the No. $j$ index of No. $i$ sample is $c_{i j}(\mathrm{mg} / 1)(i=1,2, \ldots, m ; j=1,2, \ldots, n)$. Thus the Actual-Testing-Concentration-Matrix of the water samples is:

$$
\boldsymbol{C}=\left(c_{i j}\right)_{m \times n}=\left[\begin{array}{cccc}
c_{11} & c_{12} & \cdots & c_{1 n} \\
c_{21} & c_{22} & \cdots & c_{2 n} \\
\vdots & \vdots & \vdots & \vdots \\
c_{m 1} & c_{m 2} & \cdots & c_{m n}
\end{array}\right]
$$

In order to do fuzzy evaluation to water-quality, matrix $S \& C$ will be standardized and changed into fuzzy matrix. For the water-quality standard-concentration-matrix $S$, applying standardization calculating is formulated, as follows:

$$
e_{k j}=\frac{s_{t j}-s_{k j}}{s_{t j}-s_{1 j}}
$$

Where $s_{l j}, s_{t j}, s_{k j}$ separately represents the standard concentration of water-quality grade $1, t$ and $k$. The 
standard-concentration-fuzzy-Matrix of water-quality grading is:

$$
\boldsymbol{E}=\left(e_{k j}\right)_{t \times n}=\left[\begin{array}{cccc}
e_{11} & e_{12} & \cdots & e_{1 n} \\
e_{21} & e_{22} & \cdots & e_{2 n} \\
\vdots & \vdots & \vdots & \vdots \\
e_{t 1} & e_{t 2} & \cdots & e_{t n}
\end{array}\right]
$$

Similarly, for the actual testing-concentration-matrix of water-sample, according to the opposite and positive index values, standardization calculation is conducted in this article by separately adopting formula (2), (3), as follows:

$$
\begin{gathered}
f_{i j}=\left\{\begin{array}{cl}
1, & c_{i j} \leq c_{1 j} \\
\frac{s_{t j}-c_{i j},}{s_{1 j}-s_{t j}} & s_{1 j}<c_{i j}<s_{t j} \\
0, & c_{i j} \geq s_{t j}
\end{array}\right. \\
f_{i j}=\left\{\begin{array}{cl}
1, & c_{i j} \geq s_{1 j} \\
\frac{c_{i j}-s_{t j}}{s_{1 j}-s_{t j},} & s_{t j}<c_{i j}<s_{1 j} \\
0, & c_{i j} \leq s_{t j}
\end{array}\right.
\end{gathered}
$$

thus we get the fuzzy-matrix of actual testing concentration:

$$
\boldsymbol{F}=\left(f_{i j}\right)_{m \times n}=\left[\begin{array}{cccc}
f_{11} & f_{12} & \cdots & f_{1 n} \\
f_{21} & f_{22} & \cdots & f_{2 n} \\
\vdots & \vdots & \vdots & \vdots \\
f_{m 1} & f_{m 2} & \cdots & f_{m n}
\end{array}\right]
$$

In order to get each sample's subordination under different water-quality grades, suppose:

The weighting vectors of assessing index are:

$$
\boldsymbol{W}=\left(w_{1}, w_{2}, \cdots, w_{n}\right)
$$

The actual testing concentration vectors of the No. $i$ water sample are:

$$
\boldsymbol{f}_{i}=\left(f_{i 1}, f_{i 2}, \cdots, f_{i n}\right)
$$

The standard-value vectors of water-quality Grade $k$ are:

$$
\boldsymbol{e}_{k}=\left(e_{k 1}, e_{k 2}, \cdots, e_{k n}\right)
$$

In light of the fuzziness of water grading, each sample separately belongs to its grade for the different subordination. If the subordination of water sample No. $f_{i}$ under water-quality grading standard No. $e_{k}$ is $u_{i \mathrm{k}}$ $(i=1,2, \ldots, m ; k=1,2, \ldots, t)$, then there is fuzzy-grading-matrix :

$$
\boldsymbol{U}=\left(u_{i k}\right)_{m \times t}=\left[\begin{array}{cccc}
u_{11} & u_{12} & \cdots & u_{1 t} \\
u_{21} & u_{22} & \cdots & u_{2 t} \\
\vdots & \vdots & \vdots & \vdots \\
u_{m 1} & u_{m 2} & \cdots & u_{m t}
\end{array}\right]
$$

Subordination meets the condition:

$$
\sum_{k=1}^{t} u_{i k}=1, \quad(i=1,2, \cdots, m)
$$

The difference between $f_{i}$ (water sample vector) and $e_{k}$ ( actual water-quality standard vector) can be indicated by generalized weighting distance : 


$$
d\left(\boldsymbol{f}_{i}, \boldsymbol{e}_{k}\right)=u_{i k}\left[\sum_{j=1}^{n} w_{j}\left|f_{i j}-e_{k j}\right|\right]
$$

The aim of water-quality assessment is to find the optimal fuzzy-grading-Matrix : $U=\left(u_{i k}\right)_{m \times t}$.

\section{Combination Assessment Model of Water-Quality}

As the water-quality assessment involves many biological and chemical evaluating indices; and the results of the actual testing are random; water grades takes on fuzziness. In addition, it's hard to draw a unanimous assessing conclusion through different evaluating methods. In order to make the evaluating results close to reality, two problems should be considered: First one is defining the weights of evaluating indices effectively; the second is reasonably combining two or two more represented evaluating methods together to do joint analysis. The water-quality combining evaluating model issued in this article solves above two problems effectively. The steps to construct the model are:

(1) Applying Group AHP Method to Define Weights of Evaluation Indices

In the water-quality combination evaluation model, apply Group AHP method to define the weights of evaluating indices. Suppose there are total number $n$ water-quality evaluating indices: $d_{j}(j=1,2, \ldots, n)$. Respective weights of experts in expert group (total number $s)$ are: $\lambda_{l}(l=1,2, \ldots, \mathrm{s})$, $\left(\sum_{l=l}^{s} \lambda_{l}=1\right)$. Expert $l$ is marked as the scales of 1-9. By adopting AHP practical program and human-computer dialogue to build judging-matrix $\boldsymbol{A}^{(l)}$, the maximum characteristic values and their corresponding characteristic vectors can be calculated:

$$
\boldsymbol{W}^{(l)}=\left(w_{1}^{(l)}, w_{2}^{(l)}, \cdots, w_{n}^{(l)}\right)
$$

and then the unanimity testing conducted. Weighted average integrated vector method can be applied to get the water-quality evaluating weight vectors:

$$
\boldsymbol{W}=\left(w_{1}, w_{2}, \cdots, w_{n}\right)
$$

where $w_{j}=\sum_{l=1}^{s} \lambda_{l} w_{j}^{(l)}(j=1,2, \cdots, n)$.

(2) Working Out generalized Weighted Fuzzy Grading Matrix

The optimal water fuzzy grading matrix should meet the requirement that the sum of the weighted generalized distance square between the vectors of all water samples and the vectors of each water-quality grade to be the lowest. Construct the optimization model:

$$
\left\{\begin{array}{l}
\min G\left(u_{i k}\right)=\sum_{i=1}^{m} \sum_{k=1}^{t}\left[u_{i k} \sum_{j=1}^{n}\left(w_{j}\left|f_{i j}-e_{k j}\right|\right)\right]^{2} \\
\text { s.t } \quad \sum_{k=1}^{t} u_{i k}=1, \quad u_{i k} \geq 0, \quad i=1,2, \cdots, m
\end{array}\right.
$$

and, we get: 


$$
u_{i k}=\frac{1}{\sum_{r=1}^{t}\left[\frac{\sum_{j=1}^{n} w_{j}\left|f_{i j}-e_{k j}\right|}{\sum_{j=1}^{n} w_{j}\left|f_{i j}-e_{r j}\right|}\right]^{2}}
$$

The generalized weighted fuzzy-grading-matrix $\boldsymbol{U}^{(1)}=\left(u_{i k}^{(I)}\right)_{m \times t}$.

(3) Calculating the Fuzzy Grading Matrix of Water-Quality Assessment Based on Entropy In light of the Maximum Entropy Principle of Mr. Jaynes, a two-target optimal model can be built to meet the optimization fuzzy grading matrix:

$$
\left\{\begin{array}{l}
\min P\left(u_{i k}\right)=\sum_{i=1}^{m} \sum_{k=1}^{t}\left[u_{i k} \sum_{j=1}^{n} w_{j}\left|f_{i j}-e_{k j}\right|\right]+\frac{1}{B} \sum_{i=1}^{m} \sum_{k=1}^{t} u_{i k} \ln u_{i k} \\
\mathrm{~s} \cdot \mathrm{t} \quad \sum_{k=1}^{t} u_{i k}=1, u_{i k} \geq 0, \quad i=1,2, \cdots, m
\end{array}\right.
$$

the positive parameter $B$ will be fixed according to actual matters, then:

$$
u_{i k}=\frac{\exp \left[-B \sum_{j=1}^{n} w_{j}\left|f_{i j}-e_{k j}\right|\right]}{\sum_{k=1}^{t} \exp \left[-B \sum_{j=1}^{n} w_{j}\left|f_{i j}-e_{k j}\right|\right]}
$$

we get the fuzzy grading matrix based on entropy $\boldsymbol{U}^{(2)}=\left(u_{i k}^{(2)}\right)_{m \times t}$.

(4) Figuring out Fuzzy Grading Matrix of Water-Quality Combination Evaluation If there are number $q$ types of evaluating method, we get number $q$ fuzzy grading matrixes:

$\boldsymbol{U}^{(r)}=\left(u_{i k}^{(r)}\right)_{m \times t}(r=1,2, \ldots, q)$, the water-quality grading subordinate vector of the No. $r$ evaluating method of the No. $i$ water sample is:

$$
\boldsymbol{H}_{i}^{(r)}=\left(u_{i 1}^{(r)}, u_{i 2}^{(r)}, \cdots, u_{i t}^{(r)}\right)
$$

where $\sum_{k=1}^{t} u_{i k}^{(r)}=1$.

Set the subordinate vector of the combination evaluation as:

$$
\boldsymbol{H}_{i}^{(0)}=\left(u_{i 1}^{(0)}, u_{i 2}^{(0)}, \cdots, u_{i t}^{(0)}\right)
$$

Under the condition that the sum of the deviation square is the lowest, the optimal model is constructed, as follows:

$$
\begin{cases}\min & \sum_{r=1}^{q}\left\|\boldsymbol{H}_{i}^{(0)}-\boldsymbol{H}_{i}^{(r)}\right\|^{2}=\sum_{r=1}^{q} \sum_{k=1}^{t}\left(u_{i k}^{(0)}-u_{i k}^{(r)}\right)^{2} \\ \mathrm{~s} \cdot \mathrm{t} & \sum_{k=1}^{t} u_{i k}^{(0)}=1\end{cases}
$$


the solution to the model is the only one:

$$
u_{i k}^{(0)}=\frac{1}{q} \sum_{r=1}^{q} u_{i k}^{(r)}+\frac{1}{t}\left[1-\frac{1}{q} \sum_{r=1}^{q} \sum_{k=1}^{t} u_{i k}^{(r)}\right]
$$

Given $\beta_{k}=\sum_{r=1}^{q} u_{i k}^{(r)}$, then the solution to the model can be simplified as:

$$
u_{i k}^{(0)}=\frac{1}{t}+\frac{1}{t q}\left[t \beta_{k}-\sum_{k=1}^{t} \beta_{k}\right]
$$

So fuzzy-grading-matrix of water-quality combination evaluation can be got: $\quad \boldsymbol{U}^{(0)}=\left(u_{i k}^{(0)}\right)_{m \times t}$

\section{The Example Analysis of the Water-quality Combination Evaluation of the Yangtze River}

In light of the sources released on "Report on Ecology Environment Quality of Three-Gorge Reservoir and the Middle \& Lower Reaches of Yangtze River", select four typical sections of the main stream in Yangtze River's middle reaches, which are Wuqi Dock, Chenglingji Dock, Yang Port, Three-Gorge, as the samples of polluted water. As regards detailed data, see Table 1.

According to the "Standards of Surface Water-environment Quality" (No. GB3838-83) issued by China National Environment Protection Bureau, choose $\mathrm{COD}_{\mathrm{mn}}$; BOD; Amino and Nitrogen $\left(\mathrm{NH}_{3} \& \mathrm{~N}\right)$; Volatile Phenol; Arsenic (As); Valence Six Chromium $\left(\mathrm{Cr}^{6+}\right)$ as six evaluating-indices, the surface water-quality is to be assessed on the five-grade standards.

Table 1: Data of Polluted Water Sample

\begin{tabular}{|c|c|c|c|c|c|c|}
\hline Dection & $\mathrm{COD}_{\mathrm{mn}}$ & $\mathrm{BOD}$ & $\mathrm{NH}_{3} \& \mathrm{~N}$ & Volatile Phenol & $\mathrm{As}$ & $\mathrm{Cr}^{6+}$ \\
\hline Wuqi Dock & 2.23 & 1.29 & 0.15 & 0.002 & 0.15 & 0.04 \\
\hline Chenlingji Dock & 2.64 & 1.69 & 0.37 & 0.001 & 0.06 & 0.04 \\
\hline Yang Port & 2.78 & 1.76 & 0.34 & 0.001 & 0.08 & 0.08 \\
\hline Three-Gorge & 2.81 & 1.68 & 0.52 & 0.001 & 0.08 & 0.04 \\
\hline
\end{tabular}

Based on Formula (1), (2), (3), separately work out the fuzzy matrix of water-quality grading standard and the fuzzy matrix of the actual testing concentration of water samples:

$$
\begin{aligned}
& \boldsymbol{E}=\left(e_{k j}\right)_{5 \times 6}=\left[\begin{array}{cccccc}
1 & 1 & 1 & 1 & 1 & 1 \\
0.7500 & 1 & 1 & 1 & 1 & 0.5556 \\
0.5000 & 0.8571 & 0.6667 & 0.9690 & 1 & 0.5556 \\
0.2500 & 0.5714 & 0 & 0.9180 & 0 & 0.5556 \\
0 & 0 & 0 & 0 & 0 & 0
\end{array}\right] \\
& \boldsymbol{F}=\left(f_{k j}\right)_{4 \times 6}=\left[\begin{array}{cccccc}
0.9710 & 1 & 1 & 0.9900 & 0 & 0.6660 \\
0.9200 & 1 & 1 & 1 & 0.8000 & 0.6660 \\
0.9030 & 1 & 1 & 1 & 0.4000 & 0.2220 \\
0.8990 & 1 & 0.9870 & 1 & 0.4000 & 0.6660
\end{array}\right]
\end{aligned}
$$

Based on Formula (7), (9), separately calculate the generalized weighted fuzzy grading Matrix and the 
fuzzy Matrix based on entropy ( $\operatorname{set} B=10)$ :

$$
\begin{aligned}
\boldsymbol{U}^{(1)}=\left(u_{i k}^{(1)}\right)_{4 \times 5} & =\left[\begin{array}{lllll}
0.2831 & 0.4978 & 0.1430 & 0.0610 & 0.0151 \\
0.1963 & 0.7235 & 0.0675 & 0.0098 & 0.0029 \\
0.1921 & 0.5655 & 0.1667 & 0.0521 & 0.0236 \\
0.2489 & 0.5918 & 0.1210 & 0.0302 & 0.0081
\end{array}\right] \\
\boldsymbol{U}^{(2)} & =\left(u_{i k}^{(2)}\right)_{4 \times 5}=\left[\begin{array}{lllll}
0.3117 & 0.5201 & 0.1399 & 0.0278 & 0.0005 \\
0.3173 & 0.5403 & 0.1369 & 0.0053 & 0.0002 \\
0.2092 & 0.6164 & 0.1585 & 0.0138 & 0.0016 \\
0.3083 & 0.5291 & 0.1493 & 0.0130 & 0.0003
\end{array}\right]
\end{aligned}
$$

Finally, adopt formula (11) to get the fuzzy grading matrix of combination assessment:

$$
\boldsymbol{U}^{(0)}=\left(u_{i k}^{(0)}\right)_{4 \times 5}=\left[\begin{array}{lllll}
0.2974 & 0.5090 & 0.1414 & 0.0444 & 0.0078 \\
0.2568 & 0.6319 & 0.1022 & 0.0076 & 0.0015 \\
0.2009 & 0.5910 & 0.1626 & 0.0329 & 0.0126 \\
0.2786 & 0.5605 & 0.1351 & 0.0216 & 0.0042
\end{array}\right]
$$

Judged by the maximum subordinate principle, the water-quality grade of above four sections of Yangtze River is Grade Two. This evaluating result meets the real situation.

\section{Epilogue}

The water-quality evaluation model put forward in this article is a type of new model. It improves present water-quality assessing methods, and has the characteristics of being scientific, practical and easy in operation. Analyzing the water-quality situation of Yangtze River is correct and reliable and consistent with the actual situation, so it offers scientific decision-making foundation for the continuous economy and society development of the drainage area, for the enhancing of the Water-quality monitor and drawing up the water-environment protecting program to the Yangtze River.

The method is universal and practical and effective to the assessment of atmosphere environment etc.

\section{References}

Peng Yongxing. (1994) Theory and Method of System Evaluation, Beijing: China Economic Publishing House, 310-316

Wang Lianfen. (1990) Introduction to Hierarchy Analysis Method, Beijing: Publishing House of People's University of China, 245-248

Chen Shouyu and Chen Xiaobin. (1991) Theory and Method of Water-quality Fuzzy Evaluation, Beijing: Environment and Science Transaction, 1-8, 11(1)

Zhang Chenke. (1998) "Water-quality Evaluation Model and Application of Basic Entropy," Theory and Practice of System Project 80-85, 18(6) 
